\title{
LA REFORMA DE LA FINANCIACIÓN DE LOS PARTIDOS POLÍTICOS DE 2012: ¿OTRA OPORTUNIDAD PERDIDA?
}

José Real-Dato (Universidad de Almería)*

Juan Rodríguez Teruel (Universidad de Valencia)

El 23 de octubre de 2012 se publicaba en el Boletín Oficial del Estado la Ley Orgánica 5/2012, de 22 de octubre, de reforma de la Ley Orgánica 8/2007, de 4 de julio, sobre financiación de los partidos políticos. Según su preámbulo, la ley tenía como cometido “mejorar el control de la adecuación de los ingresos y gastos de los partidos políticos al ordenamiento jurídico y a robustecer la calidad del sistema democrático”. En las siguientes páginas ofrecemos un breve análisis de los orígenes y contenido de la ley y reflexionamos sobre si, efectivamente, la nueva norma podrá con las expectativas planteadas y, en su caso, qué aspectos pueden todavía ser mejorados.

\section{El contexto de partida: la LO 8/2007}

Impulsada principalmente por los partidos de izquierda que apoyaban al gobierno del PSOE, la ley de 2007 pretendía dar respuesta a buena parte de las deficiencias detectadas (particularmente por el Tribunal de Cuentas, TCU) ${ }^{1}$ en la norma vigente hasta ese momento, la LO 3/1987, primera regulación específica sobre el tema. ${ }^{2}$ Entre

\footnotetext{
* Facultad de Derecho, Universidad de Almería, Carretera de Sacramento s/n, La Cañada de San Urbano, 04120 Almería. E-mail: jreal@ual.es.

${ }^{1}$ Véase Tribunal de Cuentas (2001) Moción relativa a la modificación de la normativa sobre financiación y fiscalización de los partidos políticos, no 541. Madrid: Tribunal de Cuentas.

${ }^{2}$ Anteriormente, la financiación de los partidos había sido regulada, de manera somera, en la Ley 54/1978 de partidos políticos y por la LO 5/1985, de régimen electoral general, en cuanto a la financiación en los períodos electorales.
} 
esos problemas estaban la necesidad de clarificación del concepto jurídico de partido para incluir en el ámbito subjetivo de control toda la organización territorial (incluyendo la municipal) e institucional (grupos parlamentarios y municipales, fundaciones y sociedades mercantiles dependientes), las insuficiencias en la delimitación y regulación de las distintas fuentes existentes, públicas y privadas (particularmente estas últimas), así como en los procedimientos contables, fiscalizador y sancionador, o la limitación del deber de depósito de las cuentas solo a los partidos con representación en el Congreso de los Diputados. En este sentido, como principales innovaciones, la ley de financiación de 2007 reconoció la financiación autonómica y local (aunque esta última quedaba fuera del control del Tribunal de Cuentas), regulaba con mayor detalle las fuentes de ingresos de los partidos, imponiendo nuevas restricciones a la llegada de dinero privado (como la prohibición de las aportaciones anónimas), prohibía a los partidos desarrollar actividades de carácter mercantil, establecía un sistema interno de control y extendía la fiscalización del TCU a las fundaciones dependientes de ellos. Estas organizaciones, que habían quedado fuera de la regulación de la ley anterior, se habían convertido en un instrumento muy importante de financiación de los partidos, al margen del escrutinio del Tribunal. La ley de 2007 también consideraba, por primera vez, el régimen tributario particular de las aportaciones efectuadas a los partidos por parte de sus miembros o de otros contribuyentes e incluía un régimen sancionador que el TCU debería encargarse de aplicar. Por último, la ley legalizaba las condonaciones de deuda de los bancos a los partidos (disposición transitoria $2^{\mathrm{a}}$ ).

Junto a estas innovaciones, de manera general, la LO 8/2007 mantenía los principios de la 3/1987 en torno a la protección estatal de los partidos, dentro un marco de financiación mixta, con niveles aumentados de regulación y control. En el contexto de bonanza económica en el que fue aprobada, el resultado sería un incremento de la aportación pública a los partidos. Así, por ejemplo, las subvenciones anuales en los Presupuestos Generales del Estado para gastos de funcionamiento crecieron, entre 2007 (primer ejercicio de aplicación de la nueva normativa) y 2011, en términos nominales, de los 65,1 a los 86,5 (un incremento del 21,1 por ciento en términos reales, descontada 
la inflación). ${ }^{3}$ El informe más reciente del TCU (el de los ejercicios 2009, 2010 y 2011, aprobado en octubre de 2013) evidencia la abrumadora dependencia de los fondos públicos de los partidos representados en las Cortes y parlamentos regionales: en 2011 recibieron 316 millones en subvenciones electorales y para funcionamiento, frente a 70,5 millones de procedencia privada (43,2 en aportaciones de militantes, afiliados y simpatizantes, 8,7 en donaciones no finalistas (5,7 de ellos procedentes de personas físicas) y el resto a través de créditos bancarios y otros tipos de aportaciones previstas por la ley (recursos propios, herencias). También muestra unos partidos altamente endeudados, (275,3 millones de euros de deuda con los bancos en 2011). Respecto a las donaciones recibidas por las fundaciones del partido - fiscalizadas desde 2007, las donaciones recibidas por las fundaciones vinculadas a los partidos, estas fueron de 7,2 millones de euros en ese año.

Pese a seguir el criterio de TCU en los cambios introducidos, este organismo continuó encontrando deficiencias que la LO 8/2007 no había resuelto. En los sucesivos informes publicados desde 2007, el Tribunal ha seguido insistiendo en la ausencia de fiscalización de las organizaciones locales y la persistencia de problemas en el régimen sancionador (omisión de una tipificación de las infracciones, inconcreción de los plazos de prescripción de éstas o limitaciones a la hora de aplicar el régimen sancionador a las fundaciones), la todavía insuficiente regulación de las fundaciones o la permisividad con las condonaciones de crédito. ${ }^{4}$

Haciendo un balance crítico de la LO 8/2007, cabe señalarse que el legislador no profundizó todo lo necesario en algunos problemas clave (flujos de dinero en el ámbito de las agrupaciones locales, aportaciones privadas a las fundaciones de los partidos, exigencia en la transparencia de las cuentas de los partidos) y, sobre todo, de debatir a fondo la filosofía del modelo. Como se ha apuntado en un trabajo previo “(p)asados más de 30 años desde el restablecimiento de la democracia en España [parecía] oportuno

\footnotetext{
${ }^{3}$ La disposición transitoria 3a de la Ley establecía, para el ejercicio 2008, la cuantía de la subvención estatal en 82,11 millones de euros.

${ }^{4}$ Véase a este respecto también la comparecencia en el Congreso de los Diputados del presidente del TCU el 8 de junio de 2010. "La banca tiene una vía ilimitada para donaciones a los partidos», El Mundo, 9 de junio de 2010.
} 
preguntarse por el sentido de una legislación muy proteccionista que pide pocas contrapartidas (más allá de la transparencia y el control) por el dinero público que reciben los partidos." 5

Estas carencias, así como la constatación de que la ley del 2007 difícilmente podría haber evitado algunos escándalos políticos que ponían en entredicho las prácticas de financiación de algunos partidos, mostraban que el campo para una reforma más profunda de la financiación de los partidos no estaba en absoluto agotado cerrado.

\section{El contenido de la LO 5/2012}

El impacto social y mediático de estos escándalos, amplificado por el contexto de la crisis económica, el subsiguiente debate sobre la corrupción política, las medidas para ponerle freno y el deterioro de la imagen pública de los partidos, devolverían el tema de la financiación de los partidos a la agenda institucional con el cambio de gobierno de noviembre de 2011.

El proyecto de ley para la reforma de la LO 8/2007 se presentaría en el Congreso de los Diputados el 11 de enero de 2012, 22 días después de la investidura del nuevo presidente del Gobierno, lo que muestra el carácter prioritario que le concedía el ejecutivo. La tramitación finalizaría casi 10 meses después, aprobándose el texto definitivo en el Senado el 10 de octubre, y publicándose en el BOE el 23 de ese mismo mes. Hay que señalar, no obstante, que la versión finalmente aprobada difiere sustantivamente del texto del proyecto enviado en un principio por el Gobierno. Éste en sintonía con las medidas de recorte en otras partidas presupuestarias puestas en marcha por el ejecutivo - únicamente recogía la reducción en la subvención pública a los gastos de funcionamiento para el ejercicio 2012 en la misma proporción en que

dicha norma las había incrementado en 2007 (20 por ciento $)^{6}$ y la eliminación de la actualización automática respecto al Índice de Precios al Consumo (IPC).

\footnotetext{
${ }^{5}$ Rodríguez, Juan, Montserrat Baras, Oscar Barberá y Astrid Barrio (2012) Finançament de partits i transparència democràtica. Bones practiques a Europea i Amèrica del Nord. Barcelona : Fundació Catalunya Europa, p. 72.
} 
El resto de modificaciones se introdujeron en el trámite parlamentario en el Congreso. Por un lado, el recorte del 20 por ciento en las subvenciones públicas fue aplicado a los montantes económicos recibidos por las asociaciones y fundaciones vinculadas a los partidos. Además, la LO 5/2012 incidió en otra de las fuentes de financiación de los partidos, las donaciones privadas, ampliando la prohibición existente que afectaba a las empresas que prestasen servicios o realicen obras para las Administraciones Públicas también, también a las empresas pertenecientes al mismo grupo o que estuviesen participadas mayoritariamente por aquéllas, a sus fundaciones, así como a cualquier fundación privada, asociación o entidad que recibiesen alguna subvención de la Administración, o cuyo presupuesto estuviese integrado por aportaciones públicas.

Otra de las medidas introducidas fue la limitación de cualquier condonación de la deuda de un partido con una entidad financiera a un máximo de 100000 euros anuales, incluyendo principal e intereses (es decir, el límite máximo permitido a las donaciones privadas).

También se otorgaba potestad al Tribunal de Cuentas y se regulaba el procedimiento para imponer sanciones por infracciones muy graves en lo tocante tanto a la financiación ordinaria como a la de los gastos electorales, ampliándose asimismo sus competencias fiscalizadoras al conjunto de las aportaciones recibidas por las fundaciones y asociaciones vinculadas a los partidos y no solamente, como hasta entonces, a las donaciones. En relación con estas organizaciones, la LO 5/2012 también estableció la no consideración como donaciones las entregas monetarias o patrimoniales hechas con la finalidad de financiar una actividad o proyecto concreto.

Por último, la ley incluía también medidas destinadas a aumentar la transparencia pública en las cuentas de los partidos, haciendo obligatoria la publicidad de sus cuentas en la página web una vez fiscalizadas por el Tribunal de Cuentas, así como de notificar a este tribunal cualquier donación superior a 50000 euros o de bienes inmuebles y de

\footnotetext{
${ }^{6}$ Ese mismo año, antes de la aprobación de la ley, el Gobierno redujo las subvenciones públicas a los partidos en la Ley de Presupuestos Generales del Estado de 2012 en casi un 13 por ciento. Véase "La financiación de los partidos cae un 12,7\%", El Mundo (edición digital), 03/04/2012 (http://www.elmundo.es/elmundo/2012/04/03/espana/1333475631.html, disponible 01/11/2013).
} 
todo acuerdo con entidades de crédito en relación a las condiciones de la deuda, debiendo hacer llegar dicha información también al Banco de España.

Estas medidas de transparencia afectaban también a las fundaciones y asociaciones vinculadas a los partidos, para las que se establece la obligación de notificar al Ministerio de hacienda información sobre todas las donaciones y aportaciones recibidas, y al Tribunal de cuentas todas las donaciones de personas jurídicas. No obstante, la ley, en una modificación de la disposición adicional séptima introducida por una enmienda del Grupo Parlamentario Popular, eximía a estas organizaciones el límite de 100000 euros anuales establecido para las donaciones privadas a los partidos procedentes de una misma persona física o jurídica; y más importante, de la prohibición de aceptación de donaciones a través de empresas contratantes con el sector público o pertenecientes a un grupo de empresas con este tipo de vínculos.

\section{Problemas persistentes en la financiación de los partidos}

La financiación ilegal de los partidos constituye una de las principales fuentes de corrupción política y, en consecuencia, afecta negativamente a la legitimidad de los propios partidos y, por extensión, dado el papel clave que estos desempeñan, a la del sistema democrático.

En este sentido, las medidas de reforma introducidas por la LO 5/2012 pretendían, según las palabras del preámbulo “mejorar el control de la adecuación de los ingresos y gastos de los partidos políticos al ordenamiento jurídico y a robustecer la calidad del sistema democrático”. No obstante, si dejamos de lado la reducción sustantiva de aportaciones públicas al Estado, el resto de elementos de la ley de 2012 constituyen cambios incrementales sobre el mismo esquema establecido en 2007.

Más relevante es quizá lo que la ley de 2012 pudo haber hecho y no hizo, carencias que han sido reflejadas por el informe del GRECO 2013². Como más destacables, en primer

\footnotetext{
${ }^{7}$ GRECO (Group d'États contre la Corruption) (2013) Third evaluation round - second compliance report on Spain: 'Incriminations (ETS 173 and 191, GPC 2)' and 'Transparency of Party Funding', 21 June 2013. Estrasburgo: GRECO Secretariat, Council of Europe.
} 


\section{Revistal herenacional de \\ Doctrina y Jurisprudencia}

lugar, la mencionada no extensión a las fundaciones de la prohibición de que empresas que están contratadas por las administraciones no puedan donar dinero a los partidos de gobierno. Esta exención expresa que la ley de 2007 hizo para las fundaciones de los partidos, y que la ley de 2012 reafirma, levanta sospechas sobre por qué lo que se considera inapropiado para los partidos no lo es tanto para sus fundaciones. Además, esa prohibición para los partido (que también se extiende a empresas vinculadas a las contratados por la administración) sólo se refiere al período durante el cual tiene vigor el contrato, por lo que, implícitamente, la norma está generando incentivos para que el intercambio de favores entre partido y empresa se extienda a lo largo del tiempo, sorteando la limitación legal.

Por otro lado, la ley de 2012 mantiene los ingresos de las organizaciones locales de los partidos fuera del ámbito de control del Tribunal de Cuentas, lo que sigue dejando en un rincón oscuro uno de los canales más prolíficos de recaudación de los partidos en los últimos años. Junto con estos, otros aspectos mejorables en la regulación y en el funcionamiento del sistema de control señalados por el informe del GRECO 2013 serían: la clarificación de los plazos y consecuencias en caso de incumplimiento de la obligación de publicación de información sobre las cuentas del partido y préstamos bancarios recibidos; la ausencia de sanciones en caso de incumplimiento del requisito de establecimiento de un sistema interno de control; la necesidad de establecer remisión de los informes internos de auditoría de los partidos al TCU; los retrasos de varios años (pese a que la ley establece el plazo en seis meses) en la publicación de los informes del TCU; o la insuficiencia del sistema de sanciones establecido (únicamente económicas, cubriendo solo parcialmente los posibles incumplimientos y de las que se excluye a los donantes). 